\title{
Correction to: The role of speckle tracking echocardiography in monitoring cardiac function in patients with hereditary hemochromatosis
}

\author{
Ludmila Danilowicz-Szymanowicz $^{1} \cdot$ Katarzyna Sikorska $^{2} \cdot$ Grzegorz Raczak $^{1}$ \\ Published online: 9 December 2019 \\ (C) Royal Academy of Medicine in Ireland 2019
}

Correction to: Irish Journal of Medical Science (2019)

$$
\text { https://doi.org/10.1007/s11845-019-02114-4 }
$$

The above article was published online with inverted given and family names of the corresponding author. Given name should be Ludmila and Danilowicz-Szymanowicz is the Family name. The correct presentation has been corrected above.

Publisher's Note Springer Nature remains neutral with regard to jurisdictional claims in published maps and institutional affiliations.

The online version of the original article can be found at https://doi.org/ 10.1007/s11845-019-02114-4

Ludmila Danilowicz-Szymanowicz

ludwik@gumed.edu.pl

1 II Department of Cardiology and Electrotherapy, Medical University of Gdansk, Debinki 7, 80-210, Gdansk, Poland

2 Department of Tropical Medicine and Epidemiology, Medical University of Gdansk, Gdansk, Poland 